\title{
Acute Myocardial Infarction. Predictors of Mortality at a Public Hospital in the City of Fortaleza, Ceará State
}

\author{
Demóstenes Gonçalves Lima Ribeiro, Pedro José Negreiros de Andrade, \\ José Nogueira Paes Júnior, Lurildo Ribeiro Saraiva \\ Fortaleza, CE - Recife, PE - Brazil
}

\begin{abstract}
Objective - To identify the clinical and demographic predictors of in-hospital mortality in acute myocardial infarction with elevation of the ST segment in a public hospital, in the city of Fortaleza, Ceará state, Brazil.
\end{abstract}

Methods - A retrospective study of 373 patients experiencing their first episode of acute myocardial infarction was carried out. Of the study patients, 289 were discharged from the hospital (group A) and 84 died (group B). Both groups were analyzed regarding: sex; age; time elapsed from the beginning of the symptoms of myocardial infarction to assistance at the hospital; use of streptokinase; risk factors for atherosclerosis; electrocardiographic location of myocardial infarct; and Killip functional class.

Results - In a univariate analysis, group B had a greater proportion of the following parameters as compared with group A: non-Killip I functional class; diabetes; age > 70 years; infarction of the inferior wall associated with right ventricular impairment; time between symptom onset and treatment at the hospital $>12 \mathrm{~h}$; anteroseptal or extensive anterior infarction; no use of streptokinase; and no tobacco use. In a multivariate logistic regression analysis, only non-Killip I functional class, diabetes, and age $>70$ years persisted as independent factors for death.

Conclusion-Non-Killip I functional class, diabetes, and age $>70$ years were independent predictors of mortality in acute myocardial infarction with elevation of the $S T$ segment.

Keywords: myocardial infarction, in-hospital mortality, Killip functional class, diabetes mellitus, elderly

Hospital de Messejana da Secretaria de Saúde do Estado do Ceará - Fortaleza Mailing address: Demóstenes Ribeiro - Rua Deputado Moreira da Rocha, 655/202 60160-060 - Fortaleza, CE, Brazil - E-mail: dribeiro@cardiol.br English version by Stela Maris C. e Gandour
Greater morbidity and mortality in acute myocardial infarction is related to its occurrence in the elderly and in females, to a delay in hospital treatment, to the presence of diabetes mellitus, to impairment of the left ventricular anterior wall or involvement of the right ventricle, to the existence of left ventricular dysfunction, and to the nonuse of coronary artery reperfusion therapy ${ }^{1}$.

In-hospital mortality in acute myocardial infarction, which was around $30 \%$ in the 1950 s, significantly declined during the past decades both in Europe and the United States (USA) ${ }^{2}$, and also in several regions of Brazil ${ }^{3,4}$, the Northeastern region included ${ }^{5}$.

Currently, with the use of thrombolytic agents or of primary angioplasty, in-hospital mortality due to acute myocardial infarction is around 8 to $10 \%$, mainly because of the benefits of early recanalization of the coronary artery related to the infarct ${ }^{6}$.

In the city of Fortaleza, in the Brazilian state of Ceará, the Hospital de Messejana of the State Secretariat of Health (HM-SESA, CE) is the major tertiary center for treating patients with acute myocardial infarction using the Sistema Único de Saúde (SUS - the Brazilian public health system). At that hospital, from 1996 to 2000 , mortality was above that reported by the Brazilian Society of Cardiology ${ }^{6}$ (tab. I). Particularities of the patients and factors related to the hospital studied may justify these numbers.

This study aimed at identifying some significant clinical and demographic predictors of in-hospital mortality in acute myocardial infarction with elevation of the ST segment easily identified on the initial admission to the emergency department or the coronary care unit.

\section{Methods}

An observational retrospective study was carried out with 373 patients experiencing their first episode of acute myocardial infarction with elevation of the ST segment, who were admitted to the HM-SESA, CE, from $01 / 01 / 96$ to 12/31/2000. 


\begin{tabular}{|lccc|}
\hline \multicolumn{4}{|c|}{$\begin{array}{c}\text { Table I - Hospitalization due to AMI - coronary care unit of the HM- } \\
\text { SESA, CE, from 01/01/96 to 12/31/00 }\end{array}$} \\
\hline Years & Patients & Deaths & $\%$ \\
\hline \multirow{2}{*}{1996} & 185 & 33 & 17.8 \\
1997 & 173 & 30 & 17.3 \\
1998 & 197 & 41 & 20.8 \\
1999 & 165 & 33 & 20 \\
2000 & 154 & 25 & 16.2 \\
Total & 874 & 162 & 18.7 \\
\hline \multirow{2}{*}{ Hospital registry book of patients of the coronary care unit of the HM-SESA, } \\
CE- 01/01/1996 to 12/31/2000.
\end{tabular}

The inclusion criterion was the first episode of acute myocardial infarction with elevation of the ST segment on the electrocardiogram, because, except for the classic contraindications to the therapy with streptokinase ${ }^{6}$, the patients selected could benefit from the use of that drug. This analysis was limited to the first episode of acute myocardial infarction, which was more easily clinically identified in the context of the emergency admission than a reinfarction would be.

To achieve the greatest homogeneity possible within the sample, the following patients were excluded: those with left bundle-branch block, or with reinfarction, or without depression of the ST segment on the electrocardiogram; those who had undergone previous myocardial revascularization surgery; those with acute myocardial infarction accompanied by congenital heart disease or nonischemic orovalvular disease; and those with acute myocardial infarction treated with primary angioplasty, because that therapy was then rarely used at the HM-SESA, CE.

The hospital registry books of the coronary care unit patients and the statistical and medical records department of the HM-SESA, CE were consulted. Of the 874 patients admitted with acute myocardial infarction during the study period, 501 were excluded from the study because they did not meet the above-cited criteria. Of the 373 patients studied, 289 were discharged from the hospital, constituting group $\mathrm{A}$, and 84 evolved to death during hospitalization, acute myocardial infarction being the primary cause, constituting group B.

The diagnosis of acute myocardial infarction with elevation of the ST segment was necessarily established by the association of clinical findings (pain or symptoms suggestive of acute myocardial infarction), typical electrocardiographic changes on admission and during hospitalization, and characteristic elevation of the enzymes ${ }^{7}$.

The 2 groups of patients were analyzed in regard to the following parameters: sex; age; place of first hospital treatment, whether at the HM-SESA, CE, or not; and time elapsed between symptom onset and hospital admission (in practice, usually defined as "delta T"), whether or not this delta $T$ was greater or smaller than 12 hours.

The following parameters were also studied: the traditional risk factors for coronary atherosclerosis; the electro- cardiographic location of the acute myocardial infarct; the use of streptokinase, or lack thereof, prior to hospital treatment; and the Killip functional class.

Streptokinase was intravenously administered at the dose of $1,500,000$ U diluted in saline solution, $5 \%$ glucose, or $5 \%$ fructose for 1 hour.

The risk factors for coronary atherosclerosis were as follows: systemic arterial hypertension, diabetes mellitus, tobacco use, hypercholesterolemia, and positive familial history for early atherosclerosis (positive familial history) ${ }^{8}$.

The topography of acute myocardial infarction was established according to the classical electrocardiographic changes, with a minimum $0.2-\mathrm{mV}$ elevation of the ST segment in 2 contiguous precordial leads and a minimum $0.1-\mathrm{mV}$ elevation of the ST segment in 2 of the inferior or lateral leads, and in the V4R lead when considering right ventricular impairment ${ }^{9}$.

Coronary artery reperfusion was not objectively analyzed. The most severe Killip functional class ${ }^{10}$ during hospitalization was analyzed for study purposes.

In regard to the statistical analysis, the outcome studied was in-hospital death. Age, in years, was portrayed as a mean value and standard deviation. Delta $T$, in hours, was portrayed as a median. A descriptive analysis of each group was provided, as were the univariate analysis and the logistic regression analysis of the variables with statistically significant differences. The Pearson chi-square test, the Fisher exact test, and the test of general similarity ratio were performed with a significance level of $5 \%$.

The odds ratio (OR) was used as a measure of association. To assess the statistical significance of the association, the null hypothesis was $\mathrm{OR}=1$.

In multiple linear regression analysis, the maximal significance level was $5 \%{ }^{11}$.

\section{Results}

The major clinical and demographic characteristics of the sample are listed in table II. In group B, the patients were older, arrived later at the hospital (HM-SESA, CE), and had a greater incidence of acute myocardial infarct of the anterior wall and of the right ventricle. In that group, as compared with group A, fewer patients received streptokinase, and more had diabetes mellitus and ventricular dysfunction.

In the sample, $27.3 \%(44 / 161)$ of the women and $18.9 \%$ (40/212) of the men died. The Fisher exact test showed that this difference in the proportions of deaths in both sexes was not statistically significant.

Of the patients $\leq 70$ years, $15.6 \%(41 / 262)$ died, and, of those $>70$ years, $38.7 \%(43 / 111)$ died. In the Fisher exact test, the proportion of deaths of the patients $>70$ years was significantly greater than that of the younger patients $(\mathrm{P}<0.001)$.

When initial treatment was provided at the Hospital de Messejana, the percentage of deaths was $26.6 \%$, and when that treatment was provided at another hospital, it was $20.0 \%$. The difference, however, was not statistically significant. 


\begin{tabular}{|c|c|c|}
\hline \multicolumn{3}{|c|}{$\begin{array}{l}\text { Table II - Major clinical and demographic characteristics of } \\
\text { the sample analyzed }\end{array}$} \\
\hline & Group A & Group B \\
\hline Total & 289 & 84 \\
\hline Males $^{1}$ & $172(59.5 \%)$ & $40(47.6 \%)$ \\
\hline Females $^{1}$ & $117(40.5 \%)$ & $44(52.4 \%)$ \\
\hline Age $^{2}$ & $60.7( \pm 12.3)$ & $69( \pm 10.2)$ \\
\hline Initial assistance at the $\mathrm{HM}-\mathrm{SESA}, \mathrm{CE}^{1}$ & $105(36.3 \%)$ & $38(45.2 \%)$ \\
\hline Median "delta T" & $06 \mathrm{~h}$ & $08 \mathrm{~h}$ \\
\hline "delta $\mathrm{T}$ " longer than 12 hours ${ }^{1}$ & $66(22.8 \%)$ & $33(39.3 \%)$ \\
\hline Smoking ${ }^{1}$ & $154(53.3 \%)$ & $33(39.3 \%)$ \\
\hline Systemic arterial hypertension ${ }^{1}$ & $146(50.5 \%)$ & $46(54.8 \%)$ \\
\hline Positive familial history ${ }^{1}$ & $125(43.3 \%)$ & $35(41.7 \%)$ \\
\hline Diabetes mellitus ${ }^{1}$ & $81(28 \%)$ & $49(58.3 \%)$ \\
\hline Hypercholesterolemia $^{1}$ & $48(22.5 \%)$ & $7(25 \%)$ \\
\hline Anteroseptal or extensive anterior AMI ${ }^{1}$ & $155(53.7 \%)$ & $53(63.1 \%)$ \\
\hline Inferior and right ventricular AMI ${ }^{1}$ & $25(8.6 \%)$ & $12(14.3 \%)$ \\
\hline AMI - other sites ${ }^{1}$ & $109(37.7 \%)$ & $19(22.6 \%)$ \\
\hline Use of streptokinase ${ }^{1}$ & $160(55.4 \%)$ & $32(38.1 \%)$ \\
\hline "Non - Killip I" ${ }^{1}$ & $68(23.5 \%)$ & $65(77.4 \%)$ \\
\hline
\end{tabular}

In regard to evolution to death in the patients treated at the hospital or not within the first 12 hours from symptom onset, $18.6 \%$ of the patients treated within the first 12 hours died, as compared with a $33.3 \%$ rate of mortality among those arriving at the HM-SESA, CE, after 12 hours of symptom onset, which was a statistically significant difference ( $\mathrm{P}<0.01$; OR: 2.19; 95\% CI: 1.30-3.67).

Among smokers, a $17.6 \%$ rate of mortality was observed, and among nonsmokers that rate was $27.4 \%$, which was a statistically significant difference. The OR estimated for nonsmokers as compared with that for smokers was 1.76 (95\% CI: 1.07-2.89).

Systemic arterial hypertension had no statistically significant association with death.

Among the patients with acute myocardial infarction and positive familial history for early atherosclerosis, the mortality rate was $21.9 \%$, and among those without that risk factor, that rate was $23.0 \%$. That difference was not statistically significant.

Mortality rate among diabetic patients reached $37.7 \%$, and, among nondiabetic patients, it was $14.4 \%$. This was a highly significant difference $(\mathrm{P}<0.0001$; OR: $3.60 ; 95.0 \% \mathrm{CI}$ : 2.17-5.95).

In regard to hypercholesterolemia, of the 241 patients assessed, $12.73 \%$ of those with elevated cholesterol levels died, and $11.29 \%$ of those with normal levels died. This difference was not statistically significant.

The mortality rates of $32.4 \%, 25.5 \%$, and $14.8 \%$ were observed respectively in acute myocardial infarcts of the inferior region and right ventricle, the anteroseptal or extensive anterior wall, and the remaining regions of the ventricular myocardium. When comparing exclusively acute myocardial infarct of the inferior region and right ventricle with that of the anteroseptal or extensive anterior wall, no significant difference was observed in regard to death. However, the
OR for death was $1.96(95 \% \mathrm{CI}: 1.09-3.49)$, when comparing acute myocardial infarction of the anteroseptal or extensive anterior wall with those of the other regions, except for the involvement of the inferior wall and of the right ventricle. Excluding the anteroseptal or extensive anterior wall involvement, OR for death reached 2.75 (95\% CI: $1.18-6.39$ ) when comparing acute myocardial infarction of the inferior region and right ventricle with those of other regions.

The mortality rate was $16.7 \%$ among the patients medicated with streptokinase, and $28.7 \%$ among those not receiving that drug with OR of 1.86 (95\% CI: $1.12-3.09$ ).

Patients with acute myocardial infarction in Killip I functional class had a $7.9 \%$ mortality rate; patients in the remaining functional classes had a mortality rate of $48.9 \%$ (P $<0.0001$ ). The OR for death was 11.12 (95\% CI: $6.23-19.83$ ).

Table III shows the factors influencing the occurrence of death with a maximal significance level of $5 \%$ in univariate analysis.

In our sample, the factors with statistical significance in the univariate analysis unfavorably influencing mortality in acute myocardial infarction with elevation of the ST segment were as follows, in decreasing order: clinical evolution of the patient in non-Killip I functional class; the presence of diabetes mellitus; age > 70 years; impairment of the inferior region and of the right ventricle; treatment at the HM-SESA, CE more than 12 hours after symptom onset; acute myocardial infarct of the anteroseptal or extensive anterior wall; nonuse of streptokinase; and the absence of tobacco use.

The results of the multiple logistic regression analysis of these variables in 373 patients, according to the Wald statistics with the backward stepwise method, were as follows: only age $>70$ years, the presence of diabetes melli-

\begin{tabular}{|c|c|c|c|c|}
\hline \multicolumn{5}{|c|}{$\begin{array}{c}\text { Table III - Percentage of patients who died, descriptive level, and OR } \\
\text { of the influencing factors (maximal significance level: } 5 \% \text { ) }\end{array}$} \\
\hline Variable & Base level & Risk level & OR & $\mathrm{P}$ \\
\hline Age group (years) & $\begin{array}{l}<70 y \\
15.6 \%\end{array}$ & $\begin{array}{l}>70 y \\
38.7 \%\end{array}$ & 3.41 & $<0.0001$ \\
\hline $\begin{array}{l}\text { Time interval (from } \\
\text { symptom onset to } \\
\text { assistance) }\end{array}$ & $\begin{array}{l}<12 \mathrm{~h} \\
18.6 \%\end{array}$ & $\begin{array}{l}>12 \mathrm{~h} \\
33.3 \%\end{array}$ & 2.19 & 0.005 \\
\hline Smoking & $\begin{array}{l}\text { Yes } \\
17.6 \%\end{array}$ & $\begin{array}{c}\text { No } \\
27.4 \%\end{array}$ & 1.76 & 0.02 \\
\hline Diabetes mellitus & $\begin{array}{c}\text { Yes } \\
14.4 \%\end{array}$ & $\begin{array}{l}\text { No } \\
37.7 \%\end{array}$ & 3.60 & $<0.0001$ \\
\hline Streptrokinase therapy & $\begin{array}{l}\text { Yes } \\
16.7 \%\end{array}$ & $\begin{array}{l}\text { No } \\
28.7 \%\end{array}$ & 1.86 & 0.02 \\
\hline Killip I & $\begin{array}{l}\text { No } \\
7.9 \%\end{array}$ & $\begin{array}{l}\text { Yes } \\
48.9 \%\end{array}$ & 11.12 & $<0.0001$ \\
\hline $\begin{array}{l}\text { Anteroseptal/ extensive } \\
\text { anterior AMI }\end{array}$ & $\begin{array}{l}\text { No } \\
14.8 \%\end{array}$ & $\begin{array}{c}\text { Yes } \\
25.5 \%\end{array}$ & 1.96 & 0.02 \\
\hline $\begin{array}{c}\text { Inferior and right } \\
\text { ventricular AMI }\end{array}$ & $\begin{array}{c}\text { No } \\
14.8 \%\end{array}$ & $\begin{array}{c}\text { Yes } \\
32.4 \%\end{array}$ & 2,75 & 0,02 \\
\hline
\end{tabular}


tus, and the absence of Killip I functional class persisted as independent factors influencing death (table IV).

The descriptive chart I shows the hypothetical chance of a certain patient of the population studied dying at the hospital due to the interaction of the above cited variables compared with another patient with none of those variables ("R risk"), some of them, or all of them.

\section{Discussion}

Of the 373 patients with the first episode of acute myocardial infarction and elevation of the ST segment, those who were discharged from the hospital differed in a greater or smaller proportion from the patients who died. The greater mortality in the female sex $(27.3 \%$ in females and $18.9 \%$ in males), contrary to what was observed in the Framingham Heart Study ${ }^{12}$ and in the study by Becker et al ${ }^{13}$, was not statistically significant.

According to those studies, infarction was more severe in females due to an intrinsic severity of the disease, to the preferential age bracket affected by the disease, or to the presence of comorbidities. However, no consensus exists in the literature in regard to the greater severity of acute myocardial infarction in females.

In the city of Rio de Janeiro, Pimenta et al ${ }^{14}$, after adjusting for all risk variables, found that female sex was a factor independently related to in-hospital mortality in acute myocardial infarction. This fact was also reported by Greenland et $\mathrm{al}^{15}$ in Israel during hospitalization or up to 1 year after hospital discharge, independent of age, of the presence of heart failure, of previous acute myocardial infarction, or of the electrocardiographic location of the infarct.

Still regarding this subject, Vaccarino et al ${ }^{16}$ reported that in acute myocardial infarction, the younger the female, the greater the chance of death as compared with males in the same age group; this difference progressively drops as age advances, becoming insignificant after the age of 74 years.

However, diverging reports exist. In statistical analysis, Hochman et al ${ }^{17}$, after adjusting for other variables, found no significant difference in mortality between males and females with that type of infarction. According to White et al ${ }^{18}$, in acute myocardial infarction treated with thrombolytic agents, after correction of the baseline clinical characteristics, females have morbidity and mortality similar to those of males, except for the greater incidence of hemorrhagic stroke.

Lincoff et al ${ }^{19}$ also found no statistically significant

\begin{tabular}{|lcc|}
\hline $\begin{array}{c}\text { Table IV - Estimate of OR for age }>\text { 70 years, absence of Killip I, and } \\
\text { presence of diabetes mellitus (Wald statistics with the backward- } \\
\text { stepwise method) }\end{array}$ \\
\hline Effects & OR & $95 \%$ CI \\
\hline Age $>70$ y & 1.8867 & $1.05-3.40$ \\
Absence of Killip I & 7.9617 & $4.33-14.63$ \\
Diabetes mellitus & 2.3389 & $1.32-4.14$ \\
\hline
\end{tabular}

difference in morbidity and mortality in acute myocardial infarction between males and females, even in regard to the occurrence of cerebral hemorrhage. Recently, in Germany, Mehilli et al ${ }^{20}$, analyzing 1937 patients with acute myocardial infarction treated with mechanical reperfusion, reported a 1-year mortality similar for both sexes, despite the more advanced age and the higher prevalence of diabetes mellitus and systemic arterial hypertension in females.

According to the latter authors, maybe due to particularities in the selection of patients, the greater mortality in acute myocardial infarction in females, even on univariate analysis, was not statistically significant, and, therefore, sex seems not to be an indicator of mortality after the first episode of infarction.

Age is an important predictor of survival after acute myocardial infarction. In England, one third to half of the patients admitted to a hospital with acute myocardial infarction are older than 70 years ${ }^{21}$, and $74.4 \%$ of the deaths due to that disease occur in patients older than 70 years ${ }^{22}$. That population is less adequately treated than are younger patients, arrives later at the hospital after the beginning of the clinical manifestations of infarction, and receives less acetylsalicylic acid, thrombolytic agents, and beta-blockers ${ }^{23}$, although they have more severe coronary artery disease.

Devlin et al ${ }^{24}$, comparing the evolution of patients with acute myocardial infarction older than 75 years with that of younger patients, found a greater percentage of heart failure and mortality among the elderly. Those authors attributed this fact to a reduction in myocardial reserve and to greater multivessel impairment, which are features that could justify the more severe evolution of acute myocardial infarction in advanced age.

Analyzing the factors influencing the occurrence of death in our sample of patients with acute myocardial infarction and elevation of the ST segment, age $>70$ years persisted as an indicator of poor evolution and was an independent factor for death with OR 1.88 (95\% CI: $1.05-3.40)$, probably related to a smaller coronary and myocardial reserve in that group.

In the 2 groups, over half the number of patients was initially treated at another hospital and, then, referred to the HM-SESA, CE, certainly translating the lack of resources or medical unsureness about treating acute myocardial infarction at those institutions. However, the simple fact of initially being or not initially being treated at the HM-SESA, $\mathrm{CE}$, did not influence mortality. A mortality rate of $26.6 \%$ was observed among those who initially sought the emergency department of the HM-SESA, CE, and a mortality rate of $20.0 \%$ was observed among those referred from another hospital. It seems that more important than being initially treated at the HM-SESA, CE, was the promptness with which the patient sought adequate medical help after symptom onset.

Coronary reperfusion therapy is beneficial when occurring within the first 12 hours of infarction presentation ${ }^{25}$, but the greatest reduction in mortality is observed in the small number of patients treated in the first 2 hours after 
symptom onset ${ }^{26}$. Comparing the 2 groups and considering the first 12 hours following acute myocardial infarction, group B patients arrived later at the hospital, and this delay had a clear influence on mortality. Of the patients being treated in the first 12 hours, $18.6 \%$ died, and of the patients arriving at the HM-SESA, CE 12 hours or longer after symptom onset, $33.3 \%$ died $(\mathrm{P}<0.01)$. The $\mathrm{OR}$ for death of the latter was $2.19(95 \% \mathrm{CI}: 1.30-3.67)$. These data are in accordance with the knowledge that, in acute myocardial infarction, the delay in adequate hospital treatment limits the execution and efficacy of therapeutical measures, mainly those related to coronary reperfusion with a clear prognostic implication ${ }^{26}$.

Piegas et al ${ }^{27}$ reported that in Brazil, only $20 \%$ of the population eligible for pharmacological thrombolysis in acute myocardial infarction receive that treatment. In our study, maybe because HM-SESA, CE is a regional referral center for the treatment of cardiovascular diseases, we observed a more frequent use of streptokinase, $55.4 \%$ of group A patients and $38.1 \%$ of group B patients, which is a mean close to the percentage of use of thrombolytic agents in the Escola Paulista de Medicina ${ }^{28}$.

Despite these numbers, as $77.2 \%$ of group A patients and $60.7 \%$ of group B patients arrived at the HM-SESA, CE within the first 12 hours of symptom onset ("delta T" $<12$ hours), some who did not receive streptokinase could not benefit from that therapy ${ }^{25}$. In fact, of the patients receiving streptokinase, $16.7 \%$ died, while of those not receiving that medication, $28.7 \%$ died $(\mathrm{P}<0.05)$.

In this study, streptokinase could have been certainly safely administered to most patients during the initial hospital treatment. Ventricular fibrillation is not more frequent in patients treated with thrombolysis than in those treated with no reperfusion ${ }^{29}$; on the contrary, its incidence is even lower in patients undergoing thrombolytic therapy, and therefore, the fear of using streptokinase in patients with acute myocardial infarction treated in the emergency department of nonspecialized hospitals is not justified.

Canto et al ${ }^{30}$ reported that, in the USA, unlike what happens with primary angioplasty, no significant difference in mortality is observed among patients medicated with a thrombolytic agent in a hospital treating a large or a small number of infarcted patients. In Israel, even in patients $>75$ years, in whom the fibrinolytic therapy determines a greater incidence of intracranial bleeding, the use of thrombolytic agents for patients with acute myocardial infarction resulted in a lower mortality rate ${ }^{31}$.

Among patients with acute myocardial infarction, the best in-hospital evolution of smokers as compared with that of nonsmokers was noteworthy. This fact, although known and reported in the literature as the "smoker's paradox", does not hold after a strict analysis in regard to its favorable influence in patients with acute myocardial infarction when considered with other variables, mainly age ${ }^{32}$. In our sample, similarly to the report by Grines et al $^{33}$, the lower mortality among smokers disappeared in the context of multivariate analysis.

Systemic arterial hypertension, hypercholesterolemia, and positive familial history for early atherosclerosis had no influence on in-hospital mortality in this group of patients with infarction even on univariate analysis.

Although in coronary artery disease diabetes mellitus interacts with other cardiovascular risk factors, in this study, diabetes mellitus was an independent predictor of mortality with an OR of 2.33 (95\% CI: $1.32-4.14$ ) for diabetic patients as compared with that of nondiabetic patients.

Knowing that acute myocardial infarction accounts for $30 \%$ of all deaths in diabetic patients ${ }^{34}$, several changes serve as the basis of the more severe evolution of these patients ${ }^{35}$, and even stress hyperglycemia in nondiabetic patients increases in-hospital mortality and the risk of heart failure and of cardiogenic shock in infarction ${ }^{36}$.

A clear association between the location of acute myocardial infarct and the occurrence of death was observed. The most frequent impairment of the left ventricular anterior wall and of the right ventricle in group B patients observed on the electrocardiogram is the major cause of the more severe condition of those patients ${ }^{37,38}$. That severity was equivalent to the severity of inferior acute myocardial infarction accompanied by impairment of the right ventricle and to the severity of anteroseptal infarction or the extensive infarction of the anterior wall, and, between them, no significant difference in regard to death exists $(\mathrm{P}=0.4199)$.

The findings of our study are in accordance with those usually reported in the literature: Hands et $\mathrm{al}^{37}$, comparing the evolution of patients with acute myocardial infarction of the anterior wall with that of patients with acute myocardial infarction of the inferior region, found a greater mortality in those patients with infarction of the anterior wall. Those authors stated that the location of infarction is an important prognostic indicator, independent of its magnitude, which is expressed by the peak in the creatine kinase levels.

According to Zehender et al ${ }^{38}$ right ventricular impairment is an independent prognostic predictor in the acute myocardial infarction of the inferior region, and it may determine, when present, high in-hospital mortality of up to $31 \%$, which is slightly lower than that found in our study.

Even before the appearance of the thrombolytic treatment or revascularization for acute myocardial infarction, the correlation between some of its forms of clinical presentation and mortality was already known. Although limited, the Killip classification for acute myocardial infarction indicates the severity of some of these manifestations ${ }^{10}$. In our study, the linear multiple regression analysis emphasized the non-Killip I functional class as an important independent predictor of mortality (tabs. III and IV).

Therefore, in our study, absence of Killip I functional class, presence of diabetes mellitus, and age $>70$ years independently translated into a greater risk of mortality in acute myocardial infarction, mainly when combined, as suggested by the hypothetical model shown in chart I.

On these bases, we suggest that, in these patients, the therapeutic strategies currently considered efficient in reducing mortality in acute myocardial infarction should be 
used preferentially and early, being initiated in the emergency department ${ }^{39,40}$.

In this study, the following factors were not independent but influenced mortality: treatment at the HM-SESA, CE after 12 hours of symptom onset; acute myocardial infarction of the anteroseptal wall or extensive anterior infarction; infarction of the inferior wall with impairment of the right ventricle; and no use of streptokinase.

Based on our findings, the population should be encouraged to seek early medical attention when symptoms suggesting acute myocardial infarction occur, to reduce the time interval between symptom onset and hospital arrival. Also, the high-risk patient should be referred to an institution able to perform immediate interventional therapy, because his prognosis is poorer with the usual or thrombolytic management than that with primary angioplasty. However, considering that in Europe less than $10 \%$ of the hospitals can perform primary angioplasty to treat acute myocardial infarction at any time of the day, 7 days a week ${ }^{41}$, that routine practice in public hospitals in the city of Fortaleza, in the state of Ceará, is unlikely to occur in a near future.

In conclusion, in this series of 373 patients with acute myocardial infarction and elevation of the ST segment, the characteristic findings that had statistical significance in the univariate analysis as predictors of death were as follows, in decreasing order: non-Killip I functional class; presence of diabetes mellitus; age $>70$ years; impairment of the inferior region associated with that of the right ventricle; time

\begin{tabular}{|c|c|c|c|}
\hline \multicolumn{4}{|c|}{$\begin{array}{l}\text { Chart I - Estimation of the risk of death, present or not, age }>70 \\
\text { years, absence of Killip I functional class, and diabetes mellitus: }\end{array}$} \\
\hline \multirow[b]{2}{*}{ Age } & \multicolumn{2}{|c|}{ Factors } & \multirow[b]{2}{*}{ Risk } \\
\hline & Killip I & D. Mellitus & \\
\hline \multirow{3}{*}{$<70 y$} & Yes & No & $\mathrm{R}$ \\
\hline & & Yes & 2.3389. R \\
\hline & No & $\begin{array}{l}\text { No } \\
\text { Yes }\end{array}$ & $\begin{array}{r}\text { 7.9617. R } \\
\text { 18.6216. R }\end{array}$ \\
\hline \multirow{4}{*}{$>70 y$} & Yes & No & 1.8867. R \\
\hline & & Yes & 4.4128. R \\
\hline & No & No & 15.0213. R \\
\hline & & Yes & 35.1334. R \\
\hline
\end{tabular}

interval longer than 12 hours from symptom onset to hospital assistance; acute myocardial infarction of the anteroseptal region or extensive anterior infarction; nonuse of streptokinase; and no smoking. On logistic regression analysis, only the first 3 findings persisted as independent factors of influence on death.

Considering that the selected sample met several exclusion criteria and was restricted to the first episode of acute myocardial infarction with elevation of the ST segment, this study had results different from those obtained with the analysis of the general population of patients with acute myocardial infarction, treated in the emergency department of the HM-SESA, CE, and certainly also in other hospitals, limiting the absolute external validity of these findings.

\section{References}

1. Lee KL, Woodlief LH, Topol EJ, et al. Predictors of 30 day mortality in the era of reperfusion for acute myocardial infarction: results from an international trial of 41021 patients. Circulation 1995; 91: 1659-68.

2. McGovern PG, Pankow JS, Shahar E, et al. The Minnesota Heart Survey Investigators. Recent trends in acute coronary heart disease. N Engl J Med 1996; 334: 884-90.

3. Marcopito LF, Shirassu MM. Mortalidade por infarto agudo do miocárdio e pelas demais doenças isquêmicas do coração no Estado de São Paulo, 1980 - 1996. Arq Bras Cardiol 2000; 75: 69-71.

4. Moraes AS, Rezende MHV, Freitas ICM. Tendência da mortalidade por doença isquêmica do coração no Município de Goiânia - Brasil na série histórica entre 1980 e 1994. Arq Bras Cardiol 2000; 74:493-7.

5. Passos LCS, Lopes AA, Lessa I, et al. Tendência da mortalidade por infarto agudo do miocárdio (1981 a 1996) na Cidade de Salvador, Brasil. Arq Bras Cardiol 2000; 74: 329-31.

6. Segunda diretriz da Sociedade Brasileira de Cardiologia para o tratamento do infarto agudo do miocárdio. Arq Bras Cardiol 2000; 74: 7-18.

7. Ryan TJ, Anderson JL, Antman EM, et al. ACC/AHA guidelines for the management of patients with acute myocardial infarction. A report of the American College of Cardiology / American Heart Association Task Force on Practice Guidelines (Committee on Management of Acute Myocardial Infarction). JAm Coll Cardiol 1996; 28:1328-428.

8. Grundy SM. Primary prevention of coronary heart disease. Integrating risk assessment with intervention. Circulation 1999; 100: 988-98.

9. Fisch C. Electrocardiography. In: Braunwald, E. (Ed). Heart Disease: a Text Book of Cardiovascular Medicine. $5^{\text {th }}$ ed. Philadelphia: WB Saunders 1997: 108-52.

10. Killip T, Kimball JT. Treatment of myocardial infarction in a coronary care unit: a two year experience with 250 patients. Am J Cardiol 1967; 20:457-64.

11. Fliess J. Statistical Methods for Rates and Proportions. $2^{\text {nd }}$ ed. New York. John Wiley \& Sons 2000.
12. Kannel WB, Sorlie P, McNamara PM. Prognosis after initial myocardial infarction: the Framingham Study. Am J Cardiol 1979; 44: 53-9.

13. Becker RC, Terrin M, Ross R, et al. Comparison of clinical outcomes for women and men after acute myocardial infarction. Ann Intern Med 1994; 120: 638-45.

14. Pimenta L, Bassan R, Potsch A, et al.É o sexo feminino um preditor independente de mortalidade hospitalar no infarto agudo do miocárdio ? Arq Bras Cardiol 200; 77: 37-43.

15. Greenland P, Reicher-Reiss H, Goldbourt U, et al. In-hospital and 1-yea mortality in 1524 women after myocardial infarction. Comparison with 4315 men. Circulation 1991; 83:484-91.

16. Vaccarino V, Parsons L, Every RN, et al. Sex-based differences in early mortality after myocardial infarction. The National Registry of Myocardial Infarction 2 Participants. N Engl J Med 1999; 341: 217-25.

17. Hochman JS, Tamis JE, Thompson DT, et al. Sex, clinical presentation and outcome in patients with acute coronary syndromes. The global use of strategies to open occluded coronary arteries in acute coronary syndromes IIb Investigators. N Engl J Med 1999; 341: 226-32.

18. White HD, Barbash GI, Modan M, et al. After correcting for worse baseline characteristics, women treated with thrombolytic therapy for acute myocardial infarction have the same mortality and morbidity as men except for a higher incidence of hemorrhagic stroke. The Investigators of the International Tissue Plasminogen ctivator/Streptokinase Mortality Study. Circulation 1993; 88 : 2097-103.

19. Lincoff AM, Califf RM, Ellis SG, et al. Thrombolytic therapy for women with myocardial infarction: is there a gender gap? Thrombolysis and Angioplasty in Myocardial Infarction Study Group. J Am Coll Cardiol 1993; 22: 1780-7.

20. Mehilli J, Kastrati A, Dirschinger J, et al. Sex-based analysis of outcome in patients with acute myocardial infarction treated predominantly with percutaneous coronary intervention. JAMA 2002; 287: 210-5.

21. McMechan SR, Adgey AAJ. Age related outome in acute myocardial infarction: elderly people benefit from thrombolysis and should be included in trials. BMJ 1998; 317: 1334-5. 
22. Marcus FI, Friday K, McCans J, et al. Age-related prognosis after acute myocardial infarction (The Multicenter Diltiazem Post-Infarction Trial). Am J Cardiol 1990; 65: 559-66

23. BarakatK, Wilkinson P, DeanerA, etal. How should age affect management of acute myocardial infarction? A Prospective Cohort Study. Lancet 1999; 353: 955-9.

24. Devlin W, Cragg D, Jacks M, et al. Comparison of outcome in patients with acute myocardial infarction aged $>75$ years with that in younger patients. Am J Cardiol 1995; 75: 573-6.

25. Indications for fibrinolytic therapy in suspected acute myocardial infarction: collaborative overview of early mortality and major morbidity results from all randomised trials of more than 1000 patients. Fibrinolytic Therapy Trialists (FTT) Collaborative Group. Lancet 1994; 343:11-22.

26. Goldberg RJ, Mooradd M, Gurwirtz JH, et al. Impact of time to treatment with tissue plasminogen activator on morbidity and mortality following acute myocardial infarction ( The Second National Registry of Myocardial Infarction). Am J Cardiol 1998; 82: 259-64.

27. Piegas LS, Rossi Neto JM. Consenso de trombólise e pós-trombólise. In: Timermann A, Machado César LA, Ferreira JFM, Bertolami MC (Ed.) Manual de Cardiologia: SOCESP. Atheneu, 2000: 182-5.

28. Carvalho AC, Gonçalves Jr, I. Trombolítico endovenoso: uso atual e perspectivas futuras. Rev Soc Cardiol Estado de São Paulo 2001; 11: VI-XXVIII.

29. Solomon SD, Ridker PM, Antman EM. Ventricular arrhythimias in trials of thrombolytic therapy for acute myocardial infarction: a meta-analysis. Circulation 1993; 88: 2575-81.

30. Canto JG, Every NR, Magid DJ, et al. The volume of primary angioplasty procedures and survival after acute myocardial infarction. National Registry of Myocardial Infarction 2 Investigators. N Engl J Med 2000; 342: 1573-80.

31. Gottlieb S, Gouldbourt U, Boyko V, et al. Improved Outcome of Elderly Patients
( $=$ or $>75$ Years of Age) with Acute Myocardial Infarction From 1981-1983 to 1992-1994 in Israel. The SPRINT and Thrombolytic Survey Groups. Secondary Prevention Reinfarction Israel Nifedipine Trial. Circulation 1997; 95: 342-50.

32. Andrikopoulos GK, Richter DJ, Dilaveris PE, et al. In-hospital mortality of habitual cigarette smokers after acute myocardial infarction. The "smoker's paradox" in a countrywide study. Eur Heart J 2001; 22: 776-84.

33. Grines CL, TopolEJ, O'Neill WW, etal. Effect of cigarette smoking on outcome after thrombolytic therapy for myocardial infarction. Circulation 1995; 91:298-303.

34. Barret-Connor E, Orchard T. Insulin dependent diabetes mellitus and ischemic heart disease. Diabetes Care 1985; 8: 65-70.

35. Nesto RW, Zarich S. Acute myocardial infarction in diabetes mellitus-Lessons Learned From ACE Inhibition. Circulation 1998; 97: 12-5.

36. Capes SE, Hunt D, Malmberg K, et al. Stress hyperglycaemia and increased risk of death after myocardial infarction in patients with and without diabetes: a systematic overview. Lancet 2000; 355: 773-8.

37. Hands ME, Lloyd BL, Robinson JS, et al. Prognostic significance of electrocardiographic site of infarction after correction for enzymatic size of infarction. Circulation 1986; 73: 885-91.

38. Zehender M, Kasper W, Kauder E, et al. Right ventricular infarction as an independent predictor of prognosis after acute inferior myocardial infarction. $\mathrm{N}$ Engl J Med 1993; 328: 981-8.

39. Boden WE, McKay RG. Optimal treatment of acute coronary syndromes - an evolving strategy. N Engl J Med 2001; 344: 1939-42.

40. Montalescot G, Barragan P, Wittenberg O, et al. Platelet glycoprotein IIb/IIIa Inhibition with coronary stenting for acute myocardial infarction. Admiral Investigators. N Engl J Med 2001; 344: 1895-903.

41. De Jaegere P P, Simoons M L. Immediate angioplasty: a conservative view from Europe: cost effectiveness needs to be considered. Br Heart J 1995; 73: 407-8. 